\title{
The exoribonuclease Polynucleotide Phosphorylase influences the virulence and stress responses of yersiniae and many other pathogens
}

\author{
Jason A. Rosenzweig ${ }^{1,2 *}$ and Ashok K. Chopra ${ }^{3,4,5,6 *}$ \\ ' Department of Biology, Center for Bionanotechnology and Environmental Research, Texas Southern University, Houston, TX, USA \\ ${ }^{2}$ Department of Environmental and Interdisciplinary Sciences, Texas Southern University, Houston, TX, USA \\ ${ }^{3}$ Department of Microbiology and Immunology, University of Texas Medical Branch, Galveston, TX, USA \\ ${ }^{4}$ Sealy Center for Vaccine Development, University of Texas Medical Branch, Galveston, TX, USA \\ ${ }^{5}$ Institute of Human Infections and Immunity, University of Texas Medical Branch, Galveston, TX, USA \\ ${ }^{6}$ Galveston National Laboratory, University of Texas Medical Branch, Galveston, TX, USA
}

\section{Edited by:}

Wyndham W. Lathem,

Northwestern University Feinberg

School of Medicine, USA

Reviewed by:

Cecilia M. Arraiano, Instituto de

Tecnologia Química e

Biológica/Universidade

Nova de Lisboa, Portugal

Kurt Schesser, University of Miami

Miller School of Medicine, USA

\section{*Correspondence:}

Jason A. Rosenzweig, Department

of Biology, 3100 Cleburne Street,

Houston, TX 77004, USA

e-mail: rosenzweigja@tsu.edu

Ashok K. Chopra, Department of

Microbiology and Immunology, 301

University Blvd., University of Texas

Medical Branch, Galveston, TX

77555-1070, USA

e-mail: achopra@utmb.edu
Microbes are incessantly challenged by both biotic and abiotic stressors threatening their existence. Therefore, bacterial pathogens must possess mechanisms to successfully subvert host immune defenses as well as overcome the stress associated with host-cell encounters. To achieve this, bacterial pathogens typically experience a genetic re-programming whereby anti-host/stress factors become expressed and eventually translated into effector proteins. In that vein, the bacterial host-cell induced stress-response is similar to any other abiotic stress to which bacteria respond by up-regulating specific stress-responsive genes. Following the stress encounter, bacteria must degrade unnecessary stress responsive transcripts through RNA decay mechanisms. The three pathogenic yersiniae (Yersinia pestis, Y. pseudo-tuberculosis, and $Y$. enterocolitica) are all psychrotropic bacteria capable of growth at $4{ }^{\circ} \mathrm{C}$; however, cold growth is dependent on the presence of an exoribonuclease, polynucleotide phosphorylase (PNPase). PNPase has also been implicated as a virulence factor in several notable pathogens including the salmonellae, Helicobacter pylori, and the yersiniae [where it typically influences the type three secretion system (TTSS)]. Further, PNPase has been shown to associate with ribonuclease E (endoribonuclease), RhIB (RNA helicase), and enolase (glycolytic enzyme) in several Gram-negative bacteria forming a large, multi-protein complex known as the RNA degradosome. This review will highlight studies demonstrating the influence of PNPase on the virulence potentials and stress responses of various bacterial pathogens as well as focusing on the degradosome-dependent and -independent roles played by PNPase in yersiniae stress responses.

Keywords: RNA decay, yersiniae, type three secretion system, host-cell induced stress response, degradosome, oxidative stress response, cold stress response

\section{INTRODUCTION}

Earlier, mRNA decay was considered a non-specific, rapid, and inevitable default pathway for all transcripts, regardless of their size and/or secondary structure (Deutscher and Li, 2001; Kushner, 2002). Presently, profound advances in our understanding of RNA decay/maturation processes and their regulation have been made (Deutscher and Li, 2001; Kushner, 2002; Silva et al., 2011). The majority of RNA decay studies have employed Escherichia coli, with limited (but a growing number of) studies performed in Gram-positive organisms (Condon and Bechhofer, 2011; Silva et al., 2011) including Bacillus subtilis (Even et al., 2005; Mäder et al., 2008; Bechhofer, 2011; Lehnik-Habrink et al., 2012), Streptococcus pyogenes (Barnett et al., 2007), Streptococcus pneumoniae (Domingues et al., 2009), and Staphylococcus aureus (Huntzinger et al., 2005; Boisset et al., 2007). Found in both Gram-positive and -negative organisms, ribonucleases are enzymes that degrade ribonucleotides.
Endoribonucleases cleave RNA molecules within the transcript while exoribonucleases degrade RNA molecules in a $3^{\prime}$ to $5^{\prime}$ or $5^{\prime}$ to $3^{\prime}$ direction (Silva et al., 2011). Of all the Gram-positive organisms interrogated, $B$. subtilis has been most extensively studied regarding ribonucleases (Even et al., 2005; Mäder et al., 2008; Bechhofer, 2011; Lehnik-Habrink et al., 2012) and PNPase specifically (Oussenko et al., 2005; Lehnik-Habrink et al., 2012).

\section{RNase E AND THE DEGRADOSOME}

The 1061 amino-acid residue long ribonuclease E (RNase E) is the predominant endoribonuclease in E. coli and is essential for cell viability. It is absent in Gram-positive organisms which instead rely on endoribonucelase/exoribonuclease J (RNase J1/J2) (Condon, 2010; Silva et al., 2011). The first 500 amino-terminal RNase E residues include both the catalytic and S1 RNA-binding domains. The carboxy-terminus (residues 734-1060) serves as a scaffolding region upon which the 
various components of the multi-protein degradosome complex bind, including the exoribonuclease polynucleotide phosphorylase (PNPase), the RNA helicase RhlB or RhlE, and enolase (a glycolytic enzyme) (Carpousis et al., 1994; Vanzo et al., 1998; Khemici and Carpousis, 2004). Specialized degradosomes of differing composition (including the association of additional accessory proteins) as well as a eukaryotic degradosome-like machine (the exosome) have also been reported in Saccharomyces cerevisiae (Lawal et al., 2011 and references therein). More specifically, a degradosome containing RNase E, the exoribonuclease RNase R, and RhlE (an RNA DEAD box helicase) was identified in the psychrotrophic bacterium Pseudomonas syringae Lz4W (Purusharth et al., 2005). Additionally, a "cold-shock degradosome" was identified in E. coli consisting of the cold-inducible DEAD box helicase CsdA/DeaD, PNPase, and other degradosome components (Prud'homme-Généreux et al., 2004).

Despite physical evidence of degradosome assembly observed in a number of organisms, the precise physiological functions carried out by these large multiprotein complexes/hyperstructures have yet to be fully elucidated (Norris et al., 2012). Using bacterial two-hybrid analysis as well as co-immunoprecipitation techniques, we recently determined that a Yersinia pseudotuberculosis degradosome, comprised of RNase E, PNPase, and RhlB helicase associates (Henry et al., 2012), extending an earlier report of physical interaction between only PNPase and RNase E in the aforementioned organism (Yang et al., 2008).

\section{PNPase}

Originally identified in E. coli, PNPase, encoded by the pnp gene, is an $\sim 80 \mathrm{kDa}$ homo-trimeric exoribonuclease that poorly degrades structured RNA molecules (Guarneros and Portier, 1991; Symmons et al., 2000). The Yersinia pestis bv. Antique's highly conserved PNPase (UniProt Entry: Q1C3L8) is a slightly smaller enzyme $(\sim 78 \mathrm{kDa})$ but shares $89 \%$ sequence similarity with that of its E. coli counterpart. Additionally, PNPase acts as a polymerase when the concentration of nucleotide di-phosphates is greater than inorganic phosphate, as shown in E. coli (Deutscher and Li, 2001). Historically, PNPase played a large part in determining the genetic code (Grunberg-Manago et al., 1955), winning Dr. Severo Ochoa the 1959 Nobel Prize in Physiology or Medicine. As mentioned above, PNPase is also a degradosome constituent in E. coli and Y. pseudotuberculosis, but exactly what percentage of PNPase's degradative effort is spent while associated with the degradosome has yet to be determined (Lawal et al., 2011). To date, the synthetic/polymerase activity of PNPase has not been demonstrated in the yersiniae. PNPase consists of two catalytic domains as well as both structurally conserved $\mathrm{KH}$ and $\mathrm{S} 1$ RNA-binding domains in its extreme carboxy-terminus.

\section{PNPase, NON-CODING sRNAs, AND Hfq (RNA-BINDING PROTEIN)}

With the discovery of functional, small non-coding RNA molecules (sRNAs) involved in regulating gene expression, the entire paradigm associated with "what constitutes a gene" was shifted. sRNAs became increasingly studied when they were found to influence bacterial physiology and even virulence (Gottesman et al., 2001; Shimoni et al., 2007; Repoila and Darfeuille, 2009; Silva et al., 2011; Storz et al., 2011). More specifically, in E. coli,
PNPase was found to stabilize several regulatory sRNAs including: RyhB, SgrS, and CyaR. Further, RNase E appeared responsible for their increased turnover/decay in the absence of PNPase (De Lay and Gottessman, 2011). These findings strongly suggest that the degradosome assembly (which includes the presence of PNPase) is required for stabilizing some regulatory sRNAs in $E$. coli. Perhaps the degradosome is protecting virulence-regulating sRNAs in bacterial pathogens as well?

In Y. pseudotuberculosis, 150 sRNA species (Koo et al., 2011) have been identified, many of which are involved in Yersinia virulence (Koo and Lathem, 2012; Lathem, 2012). Upon proteome profiling, the SraG sRNA was found to regulate expression of 16 different genes as evidenced by differential protein expression in Y. pseudotuberculosis. Interestingly, SraG appeared to positively regulate levels of PNPase, one of the 16 differentially expressed proteins (Lu et al., 2012). These powerful sRNAs used for modulating gene expression complement other post-transcriptional regulating factors including: ribonucleases (e.g., PNPase), RNAbinding proteins, and thermal riboswitches (e.g., the low calcium response at $37^{\circ} \mathrm{C}$ ) (Schiano and Lathem, 2012).

In many instances, Hfq (an RNA-binding protein) will bind to sRNAs either promoting their stabilization or degradation (Silva et al., 2011). In the case of Yersinia pestis, 31 unique sRNAs were discovered, and the majority of those required the presence of Hfq for their expression (Beauregard et al., 2013). A separate global analysis of sRNAs revealed as many as 43 species in $Y$. pestis (Qu et al., 2012). Further, of the two Y. pestis iron-responsive sRNA RyhB homologs, only RhyB1 required Hfq for stabilization while RyhB2's stability was Hfq-independent (Deng et al., 2012). Further, PNPase has been shown to play a crucial role in the degradation of sRNAs that do not associate with Hfq (Andrade et al., 2012).

However, in E. coli, Hfq was shown to be necessary for PNPasemediated degradation of the Cold shock Protein A encoding transcript ( $\operatorname{csp} A)$ during cold shock (Hankins et al., 2010). Hfq also influences the virulence of a number of pathogenic bacteria (Chao and Vogel, 2010) including Y. pestis and Y. pseudotuberculosis (Geng et al., 2009; Schiano et al., 2010), while also influencing the growth of the latter (Bai et al., 2010). Perhaps Hfq is the link between yersiniae PNPase, sRNAs, and bacterial virulence?

\section{PNPase AND COLD SHOCK/COLD GROWTH}

Bacterial responses to low temperature stress are generally referred to as "cold shock." PNPase confers cold growth capabilities to a number of bacteria (including several pathogens) including: E. coli, the yersiniae, Salmonella enterica, Campylobacter jejuni, S. aureus, and B. subtilis (Jones et al., 1987; Wang and Bechhofer, 1996; Goverde et al., 1998; Clements et al., 2002; Rosenzweig et al., 2005, 2007; Anderson and Dunman, 2009; Haddad et al., 2009, 2012). Considering that C. jejuni and several pathogenic yersiniae are contracted via the fecal oral route, PNPase could serve to promote bacterial persistence on processed meats that are shipped at refrigerated temperatures (thereby facilitating foodborne illness).

During the cold shock response in E. coli, cold inducible genes, including six cold shock protein genes (csp's), become upregulated (Jones et al., 1987; Goldstein et al., 1990). Additionally, 
cold-inducible $p n p$ and $r n r$ genes, encoding PNPase and RNase $\mathrm{R}$ respectively, were also found to be cold-inducible in E. coli (Jones et al., 1987; Cairrão et al., 2003). Interestingly, RNase R was required for specifically degrading ompA transcript (encoding outer membrane protein $\mathrm{A}-\mathrm{OmpA}$ ) during stationary phase growth of E. coli (Andrade et al., 2006), strongly suggesting that RNase $\mathrm{R}$ is not only cold-inducible but also growth-phase inducible.

During acclimation, immediately following cold-shock, PNPase is required for degradation of unnecessary csp (that likely trap ribosomes) and other cold-inducible transcripts in both E. coli and Yersinia enterocolitica (Goverde et al., 1998; Neuhaus et al., 2000; Yamanaka and Inouye, 2001; Polissi et al., 2003). More specifically, in Y. enterocolitica PNPase, together with RNase E, influences cold growth adaptation through its recognizing and cleaving AGUAA motifs (termed cold-shock-cut boxes) in $\operatorname{csp}$ transcripts (Neuhaus et al., 2003). Furthermore, the ability of PNPase to promote cold growth in the yersiniae absolutely required the catalytic activity of PNPase and to a lesser extent its RNA-binding domains, the S1 RNA-binding domain more than the KH RNA-binding domain (Rosenzweig et al., 2005). Surprisingly, we found that PNPase was not required for chemical stress responses associated with antibiotic exposures that target protein translational machinery, the cellular membrane, and the yersiniae cell wall (Henry et al., 2012), indicating that PNPase might not be a global stress regulator but rather a regulator of specific encountered stresses in yersiniae, like the cold temperature stress.

\section{PNPase AND BACTERIAL VIRULENCE}

PNPase influences the virulence of number of human pathogens as well as one animal pathogen. In the Gram-negative Dichelobacter nodosus (the etiological agent of foot root in sheep), PNPase was found to negatively regulate virulence/twitching motility, primarily through its S1 RNA-binding domain (Palanisamy et al., 2010). Whether animal or human pathogens, when Gram-negative pathogens, including the yersiniae and salmonellae, are confronted by threatening innate immune cells, a rapid genetic re-programming occurs resulting in anti-host type three secretion system (TTSS) genes becoming upregulated (Cornelis and Van Gijsegem, 2000; Cornelis, 2002; Viboud and Bliska, 2005). It has now been firmly established that a number of ribonucleases (e.g., PNPase, RNase R, RNase $\mathrm{E}$, RNase III) influence bacterial virulence in a wide range of Gram-negative and -positive pathogens (Anderson and Dunman, 2009; Lawal et al., 2011; Jester et al., 2012; Matos et al., 2012). Specifically, PNPase was required for the optimal virulence of several bacterial human pathogens (Table 1), in several instances by targeting TTSS targets.

In S. enterica, PNPase is required for optimal virulence in both mouse and cell culture infection models (the latter causing acute infections). However, in a seemingly counter-intuitive observation, PNPase works to negatively regulate macrophage invasion and expression of type TTSS genes involved in macrophage invasion (Clements et al., 2002). Additionally, PNPase works to also negatively regulate Salmonella plasmid virulence genes $(s p v)$ transcript levels by acting through the $s p v$ activator/regulator $s p v R$,
Table 1 | List of PNPase influences on various bacterial pathogens.

\begin{tabular}{|c|c|c|}
\hline Organism & PNPase role & References \\
\hline \multirow[t]{3}{*}{$\begin{array}{l}\text { Salmonella } \\
\text { enterica }\end{array}$} & Promotes cold growth & $\begin{array}{l}\text { Clements et al., } \\
2002\end{array}$ \\
\hline & $\begin{array}{l}\text { Promotes acute infection and } \\
\text { virulence in murine infections }\end{array}$ & $\begin{array}{l}\text { Clements et al., } \\
2002\end{array}$ \\
\hline & $\begin{array}{l}\text { Suppresses Salmonella } \\
\text { plasmid virulence genes }\end{array}$ & $\begin{array}{l}\text { Ygberg et al., } \\
2006\end{array}$ \\
\hline $\begin{array}{l}\text { Yersinia } \\
\text { enterocolitica }\end{array}$ & Promotes cold growth & $\begin{array}{l}\text { Goverde et al., } \\
1998\end{array}$ \\
\hline \multirow[t]{2}{*}{$\begin{array}{l}\text { Yersinia pseu- } \\
\text { dotuberculosis }\end{array}$} & Promotes cold growth & $\begin{array}{l}\text { Rosenzweig } \\
\text { et al., } 2005\end{array}$ \\
\hline & $\begin{array}{l}\text { Promotes virulence in murine } \\
\text { and cell culture infections }\end{array}$ & $\begin{array}{l}\text { Rosenzweig } \\
\text { et al., } 2007\end{array}$ \\
\hline \multirow[t]{2}{*}{ Yersinia pestis } & $\begin{array}{l}\text { Promotes virulence in cell } \\
\text { culture infection and optimal } \\
\text { TSSS function }\end{array}$ & $\begin{array}{l}\text { Rosenzweig } \\
\text { et al., } 2005\end{array}$ \\
\hline & $\begin{array}{l}\text { Promotes virulence in Swiss } \\
\text { Webster murine IP infections }\end{array}$ & Lawal et al., 2011 \\
\hline $\begin{array}{l}\text { Dichelobacter } \\
\text { nodosus }\end{array}$ & $\begin{array}{l}\text { Suppresses virulence and } \\
\text { twitching motility }\end{array}$ & $\begin{array}{l}\text { Palanisamy } \\
\text { et al., } 2010\end{array}$ \\
\hline $\begin{array}{l}\text { Campylobacter } \\
\text { jejuni }\end{array}$ & Promotes cold growth & $\begin{array}{l}\text { Haddad et al., } \\
2009,2012\end{array}$ \\
\hline $\begin{array}{l}\text { Staphylococcus } \\
\text { aureus }\end{array}$ & Promotes cold growth & $\begin{array}{l}\text { Anderson and } \\
\text { Dunman, } 2009\end{array}$ \\
\hline $\begin{array}{l}\text { Streptococcus } \\
\text { pyogenes }\end{array}$ & $\begin{array}{l}\text { Degrades virulence } \\
\text { transcripts during late } \\
\text { exponential phase }\end{array}$ & $\begin{array}{l}\text { Barnett et al., } \\
2007\end{array}$ \\
\hline $\begin{array}{l}\text { Streptococcus } \\
\text { mutans }\end{array}$ & $\begin{array}{l}\text { Is upregulated during } \\
\text { acid-shock }\end{array}$ & Len et al., 2004 \\
\hline
\end{tabular}

TTSS, Type three secretion system.

thereby reducing intracellular survival of S. enterica (Ygberg et al., 2006). In Salmonella, PNPase might be acting as a molecular switch, whereby a persistent infection is caused unless active PNPase promotes acute infections.

As was the case for the cold shock response, following host immune cell stress, the yersiniae must resume pre-stress gene expression profiles through the removal of unwanted and unnecessary TSSS-associated transcripts. Is PNPase, and, by extension, the degradosome involved in this post-TTSS acclimation following the host-cell encounter. This question becomes even more interesting when considering that both the RNA degradosome and the T3SS are large multi-protein hyperstructure complexes that could be interacting (Norris et al., 2012). Of the 11 known Gram-negative Yersinia spp., only Y. enterocolitica, $Y$. pseudotuberculosis, and $Y$. pestis are human pathogens. While fecal-oral transmission of Y. pseudotuberculosis and Y. enterocolitica causes self-limiting gastroenteritis (Galindo et al., 2011), $Y$. pestis (transmitted by the bite of an infected flea) has caused 
three major human pandemics as well as the great plagues of London in the 1660s (Inglesby et al., 2000). In both Y. pestis and $Y$. pseudotuberculosis, PNPase was required for optimal virulence in cell culture infections (as measured by bacterial proliferation vis a vis mouse macrophage-like cells and degree of induced HeLa cell rounding, an indirect measure of TTSS function) (Rosenzweig et al., 2005) as well as in murine models of infection (Rosenzweig et al., 2007; Lawal et al., 2011). Interestingly, there was no evidence of PNPase reducing TTSS promoter activity in $Y$. pseudotuberculosis wild type and $\Delta p n p$ deletion mutants that harbored a yopE::gfp (Rosenzweig et al., 2005). In contrast, PNPase was required for robust Yop D and E secretion during an early kinetic TTSS induction window (between 0 and $20 \mathrm{~min}$ ), but not for optimal Yop production levels (Rosenzweig et al., 2005). Counter-intuitively, PNPase promotes robust Yop secretion during initial TTSS induction despite negatively regulating T3SS transcript and protein production levels (Rosenzweig et al., 2007).

Interestingly, different PNPase determinants were required for various yersiniae stress responses (Table 2). Whereas PNPase's catalytic activity was dispensable for inducing HeLa cell rounding, it was absolutely required during cold stress (Rosenzweig et al., 2005). However, it was PNPase's S1 RNA-binding domain that proved necessary for inducing optimal HeLa cell rounding. In fact, S1 RNA-binding domains (derived from exoribonucleases PNPase, RNase II, and RNase R) alone were sufficient in complementing the yersiniae $\Delta p n p$ deletion mutants when expressed in trans (Rosenzweig et al., 2005). Furthermore, the minimal S1 domain region required for $\Delta p n p$ complementation in TTSS function and HeLa cell cytotoxicity was later determined to be amino acid residues 65-125 (Rosenzweig et al., 2007).

Within the required 65-125 amino acid S1 domain region, we were able to identify the specific S1 domain residue (F638), which proved necessary for not just TTSS function (as measured by HeLa cell rounding) but also cold growth (Rosenzweig et al.,
2007). The yersiniae PNPase F638 is highly conserved and present not just in the S1 domain of E. coli PNPase but also in the S1 domain of E. coli RNase E at reside F57 (Diwa et al., 2002). Further, a co-crystal structural determination revealed that within the catalytic core of E. coli's RNase E that includes its S1 domain, the F57 residue (conserved with PNPase's F638) might play a facilitating role in binding RNA while residues F67 and K112 actually contact the RNA molecule (Callaghan et al., 2005). Since our previous studies revealed that both the cold-stress response as well as the HCISR require the S1 RNA-binding domain of PNPase (Rosenzweig et al., 2005, 2007; Henry et al., 2012), perhaps an as of yet unidentified upstream regulator (or novel factor) will converge on the PNPase S1 domain's RNA-binding property?

When considering that PNPase confers cold growth capabilities to a number of bacterial pathogens including $Y$. pestis, $Y$. enterocolitica, Y. pseudotuberculosis, S. enterica, C. jejuni, and S. aureus (Goverde et al., 1998; Clements et al., 2002; Rosenzweig et al., 2005, 2007; Anderson and Dunman, 2009; Haddad et al., 2009, 2012), PNPase acts as a "virulence empowering factor" by enhancing the pathogens' survival during adverse/hostile environmental conditions. In another striking example of this, PNPase becomes upregulated $\sim 4$-fold in the dental pathogen, Streptococcus mutans during acid-shock/encounters with low $\mathrm{pH}$ (Len et al., 2004). Perhaps, in the same way PNPase serves as a "virulence empowering factor" during low temperature exposure, it may be enhancing the survival of an oral pathogen when local environments on tooth surfaces become acidic during decay? In another Gram-positive pathogen, PNPase appeared to play a role in $S$. pyogenes sag A (a virulence transcript encoding a streptolysin) and $s d a$ (encoding an anti-neutrophil DNase) degradation during late-exponential growth phase (Barnett et al., 2007). Taken together, PNPase appears to influence the virulence potential and/or survival of a broad range of pathogens, including the pathogenic yersiniae.

Table 2 | List of PNPase determinants in yersiniae stress responses.

\begin{tabular}{|c|c|c|c|}
\hline Organism & $\begin{array}{l}\text { Degradosome- } \\
\text { dependence }\end{array}$ & PNPase role & References \\
\hline \multirow[t]{3}{*}{ Yersinia pestis } & $?$ & Catalytic activity plays an essential role in cold growth & Rosenzweig et al., 2005 \\
\hline & $?$ & S1 domain sufficient for mediating virulence & Rosenzweig et al., 2005 \\
\hline & $?$ & $\begin{array}{l}\text { The first } 15 \text { aa residues of the } S 1 \text { domain are dispensable for virulence; } \\
\text { however, the first } 30 \text { aa residues are required for virulence }\end{array}$ & Rosenzweig et al., 2007 \\
\hline \multirow{3}{*}{$\begin{array}{l}\text { Yersinia } \\
\text { pseudotuberculosis }\end{array}$} & No & $\mathrm{S} 1$ and $\mathrm{KH}$ domains also contribute to cold growth. & Rosenzweig et al., 2005 \\
\hline & No & Degradosome-independent role in cold growth & Henry et al., 2012 \\
\hline & Yes & Degradosome assembly required for virulence & Yang et al., 2008 \\
\hline
\end{tabular}

S1, RNA-binding domain; KH, RNA-binding domain. 


\section{DO RIBONUCLEASES OTHER THAN PNPaSe CONTRIBUTE TO BACTERIAL STRESS RESPONSES?}

PNPase is not the sole ribonuclease involved in bacterial stress responses. As mentioned earlier, RNase $\mathrm{R}$ was shown to be upregulated in E. coli as well as being necessary for optimal cold growth (Cairrão et al., 2003). However, in Y. pestis neither RNase $\mathrm{R}$ nor RNase II was necessary for cold growth in the yersiniae (Lawal et al., 2013). That does not, however, necessarily mean that RNase R and/or RNase II are not also up-regulated in the yersiniae during cold stress, something that has yet to be determined. Interestingly, RNase $\mathrm{R}$ has been shown to play a role in the HCISR of S. flexnari (Tobe et al., 1992), Aeromonas hydrophila (Erova et al., 2008), and H. pylori (Tsao et al., 2009). In contrast, RNase R did not appear necessary for $Y$. pestis virulence (Rosenzweig et al., 2005). With regards to the yersiniae, it seems that PNPase specifically influences cold (Rosenzweig et al., 2005, 2007; Henry et al., 2012), oxidative (Henry et al., 2012), and host-cell induced stress responses (Rosenzweig et al., 2005, 2007).

\section{DEGRADOSOME DEPENDENCE FOR YERSINIAE VIRULENCE AND DURING OXIDATIVE STRESS BUT NOT DURING COLD STRESS}

Using bacterial two-hybrid analysis as well as coimmunoprecipitation techniques, the $Y$. pseudotuberculosis degradosome was determined to contain RNase E, PNPase, and RhlB helicase (Henry et al., 2012), extending an earlier report of physical interaction between only PNPase and RNase E in the aforementioned organism (Yang et al., 2008). To create a degradosome assembly-incompetent $Y$. pseudotuberculosis strain, a dominant-negative, truncated RNase E variant (residues 1-465), containing only its amino terminal catalytic and S1 domains, was ectopically expressed (Briegel et al., 2006; Yang et al., 2008). RNase E autoregulates itself post-transcriptionally; however, when the aforementioned dominant-negative variant was expressed, its autoreagulatory activity was inhibited (Briegel et al., 2006; Yang et al., 2008). Since the carboxy-terminal degradosome scaffolding region was absent when the above mentioned dominant-negative variant was expressed, the yersiniae degradosome could not assemble, as was seen in Y. pseudotuberculosis (Yang et al., 2008).

To determine whether degradosome assembly was required for yersiniae virulence, both a proliferation assay in co-culture with macrophage-like cells as well as a TTSS functional evaluation were carried out. Interestingly, Y. pseudotuberculosis proliferation was significantly reduced when the degradosome was unable to assemble (Yang et al., 2008). In fact, the degree of reduced proliferation mirrored that of the yersiniae $\Delta p n p$ deletion mutants observed earlier (Rosenzweig et al., 2005). Furthermore, Yang et al. (2008) were able to demonstrate that degradosome assembly was also necessary for optimum TTSS function, as measured by YopE secretion. Again, this diminished TTSS function resembled that of the yersiniae $\Delta p n p$ deletion mutants (Rosenzweig et al., 2005, 2007). Taken together, these data collectively demonstrated that the yersiniae requirement for PNPase to achieve optimal virulence is degradosome-dependent.

Was the PNPase contribution to yersiniae cold-growth degradosome-dependent or -independent, and did PNPase contribute to the oxidative stress response? To address this, the dominant-negative, truncated RNase E variant, residues 1-465 (Yang et al., 2008), was again employed. Interestingly, the $Y$. pseudotuberculosis PNPase confers cold-growth capability in a degradosome-independent manner while PNPase responds to oxidative stress, in the form of $\mathrm{H}_{2} \mathrm{O}_{2}$ exposure, in a degradosomedependent manner (Henry et al., 2012). The yersiniae degradosome dependence for optimal virulence (Yang et al., 2008) does, however, logically align itself with our finding that the Yersinia oxidative stress response also requires PNPase in a degradosomedependent manner (Henry et al., 2012) since, during the host-cell stress, the yersiniae are likely to encounter host-cell generated reactive oxygen species.

In sharp contrast, the PNPase requirement of E. coli during oxidative stress was degradosome-independent since an RNase E truncated variant devoid of the degradosome scaffolding region did not demonstrate compromised growth when exposed to $\mathrm{H}_{2} \mathrm{O}_{2}$ (Wu et al., 2009). In E. coli, PNPase independently prevented the accumulation of oxidatively damaged RNA (Wu et al., 2009). Curiously, however, PNPase, itself, was required for the optimal oxidative stress response in both E. coli and Y. pseudotuberculosis (Wu et al., 2009; Henry et al., 2012). Taken together, these data clearly demonstrate that PNPase contributes to various stress responses differently, at times by associating with the degradosome hyperstructure (as in the case of the yersiniae oxidative and host-cell stress response).

\section{CONCLUSION}

Throughout the literature, many examples of how ribonucleases impact bacterial virulence are apparent (Lawal et al., 2011; Matos et al., 2012; Jester et al., 2012). Whereas RNase R and RNase II have been evaluated for their impacts on bacterial virulence and various stress responses in numerous organisms, detailed studies of the aforementioned ribonucleases in the yersiniae have yet to be carried out. However, PNPase has been well-characterized in the yersiniae and found to be essential for cold growth (Goverde et al., 1998; Rosenzweig et al., 2005), required for optimal T3SS activity (Rosenzweig et al., 2005, 2007), oxidative stress responses (Henry et al., 2012), and yersiniae virulence(Rosenzweig et al., 2005). In fact, the yersiniae are not alone when it comes to dependence on PNPase for optimal virulence. S. enterica and $D$. nodosus also require PNPase for optimal virulence, while PNPase works to enhance survival of C. jejuni, S. aureus, S. pyogenes, and $S$. mutans during unfavorable conditions (Table 1). With regards to PNPase's contributions to yersiniae virulence, degradosome assembly was required, indicating that PNPase likely mediates its effect through the larger degradosome hyperstructure. Furthermore, this implicated RNase E, the chief endoribonuclease and scaffold upon which the degradosome assembles, as a virulence-associated factor (Yang et al., 2008).

Despite our furthering the aforementioned study, to determine that yersiniae degradosome assembly was also necessary for oxidative stress responses but not cold stress responses (Henry et al., 2012), still much remains unknown, specifically about the role of other ribonucleases during yersiniae stress responses. Furthermore, the precise mechanism by which PNPase (either in a degradosome-dependent or -independent manner) mediates the specific stress responses mentioned earlier also remains 
unclear. For example, whether PNPase is degrading a repressor/negative regulator or binding to (through its S1 RNA-binding domain) and protecting an activator/positive regulator remains unknown during the various stress responses. Although progress has been made on understanding the roles the ribonucleases and RNA metabolism during various bacterial stress responses, a broader survey of additional ribonucleases should be carried out in the yersiniae, possibly revealing novel chemotherapeutic targets and/or novel vaccine candidate strains.

\section{ACKNOWLEDGMENTS}

We would like to greatly acknowledge lively discussions and insights provided by Ambro van Hoof, Abidat Lawal, Kurt Schesser, and Greg Plano. Work on this chapter was supported by National Aeronautics and Space Administration (NASA) cooperative agreement NNX08B4A47A (Jason A. Rosenzweig), and NIH/NIAID AI064389 grant awarded to Ashok K. Chopra.

\section{REFERENCES}

Anderson, K. L., and Dunman, P. M. (2009). Messenger RNA turnover processes in Escherichia coli, Bacillus subtilis, and emerging studies in Staphylococcus aureus. Int. J. Microbiol. 2009, 525491. doi: 10.1155/2009/525491

Andrade, J. M., Cairrão, F., and Arraiano, C. M. (2006). RNase R affects gene expression in stationary phase: regulation of ompA. Mol. Microbiol. 60, 219-228. doi: 10.1111/j.1365-2958.2006.05092.x

Andrade, J. M., Pobre, V., Matos, A. M., and Arraiano, C. M. (2012). The crucial role of PNPase in the degradation of small RNAs that are not associated with Hfq. RNA 18, 844-855. doi: 10.1261/rna.029413.111

Bai, G., Golubov, A., Smith, E. A., and McDonough, K. A. (2010). The importance of the small RNA chaperon Hfa for growth of epidemic Yersinia pestis, not Yersinia pseudotuberculosis, with implications for plague biology. J. Bacteriol. 192, 4239-4245. doi: 10.1128/JB.00504-10

Barnett, T. C., Bugrysheva, J. V., and Scott, J. R. (2007). Role of mRNA stability in growth phase regulation of gene expression in the group A Streptococcus. J. Bacteriol. 189, 1866-1873. doi: 10.1128/JB.01658-06

Beauregard, A., Smith, E. A., Petrone, B. L., Singh, N., Karch, C., McDonough, K. A., et al. (2013). Identification and characterization of small RNAs in Yersinia pestis. RNA Biol. 10, 397-405. doi: 10.4161/rna.23590

Bechhofer, D. H. (2011). Bacillus subtilis mRNA decay: new parts in the toolkit. Wiley Interdiscip. Rev. RNA 2, 387-394. doi: 10.1002/wrna.66

Boisset, S., Geissmann, T., Huntzinger, E., Fechter, P., Bendridi, N., Possedko, M., et al. (2007). Staphylococcus aureus RNAIII coordinately represses the synthesis of virulence factors and the transcription regulator Rot by an antisense mechanism. Genes Dev. 21, 1353-1366. doi: 10.1101/gad.423507

Briegel, K. J., Baker, A., and Jain, C. (2006). Identification and analysis of Escherichia coli ribonuclease E dominant-negative mutants. Genetics 172, 7-15. doi: 10.1534 /genetics.105.048553

Cairrão, F., Cruz, A., Mori, H., and Arraiano, C. M. (2003). Cold shock induction of RNase $\mathrm{R}$ and its role in the maturation of the quality control mediator SsrA/tmRNA. Mol. Microbiol 50, 1349-1360. doi: 10.1046/j.13652958.2003.03766.x

Callaghan, A. J., Marcaida, M. J., Stead, J. A., McDowall, K. J., Scott, W. G., and Luisi, B. F. (2005). Structure of Escherichia coli RNase E catalytic domain and implications for RNA turnover. Nature 437, 1187-1191. doi: 10.1038/nature04084

Carpousis, A. J., Van Houwe, G., Ehretsmann, C., and Krisch, H. M. (1994). Copurification of E. coli RNAase E and PNPase: evidence for a specific association between two enzymes important in RNA processing and degradation. Cell 76, 889-900. doi: 10.1016/0092-8674(94)90363-8

Chao, Y., and Vogel, J. (2010). The role of Hfq in bacterial pathogens. Curr. Opin. Microbiol. 13, 24-33. doi: 10.1016/j.mib.2010.01.001

Clements, M. O., Eriksson, S., Thompson, A., Lucchini, S., Hinton, J. C., Normark, S., et al. (2002). Polynucleotide phosphorylase is a global regulator of virulence and persistency in Salmonella enterica. Proc. Natl. Acad. Sci. U.S.A. 99, 8784-8789. doi: 10.1073/pnas.132047099
Condon, C. (2010). What is the role of RNase J in mRNA turnover? RNA Biol. 7, 316-321. doi: 10.4161/rna.7.3.11913

Condon, C., and Bechhofer, D. H. (2011). Regulated RNA stability in the gram positives. Curr. Opin. Microbiol. 14, 148-154. doi: 10.1016/j.mib.2011.01.010

Cornelis, G. R. (2002). Yersinia type III secretion: send in the effectors. J. Cell Biol. 158, 401-408. doi: 10.1083/jcb.200205077

Cornelis, G. R., and Van Gijsegem, F. (2000). Assembly and function of type III secretory systems. Annu. Rev. Microbiol. 54, 735-774. doi: 10.1146/annurev.micro.54.1.735

De Lay, N., and Gottessman, S. (2011). Role of polynucleotide phosphorylase in sRNA function in Escherichia coli. RNA 17, 1172-1189. doi: 10.1261/rna.2531211

Deng, Z., Meng, X., Su, S., Liu, Z., Ji, X., Zhang, Y., et al. (2012). Two sRNA RyhB homologs from Yersinia pestis biovar microtus expressed in vivo have differential Hfq-dependent stability. Res. Microbiol. 163, 413-418. doi: 10.1016/j.resmic.2012.05.006

Deutscher, M. P., and Li, Z. (2001). Exoribonucleases and their multiple roles in RNA metabolism. Prog. Nucleic Acid Res. Mol. Biol. 66, 67-105. doi: 10.1016/S0079-6603(00)66027-0

Diwa, A. A., Jiang, X., Schapira, M., and Belasco, J. G. (2002). Two distinct regions on the surface of an RNA-binding domain are crucial for RNase E function. Mol. Microbiol. 46, 959-969. doi: 10.1046/j.1365-2958.2002.03231.x

Domingues, S., Matos, R. G., Reis, F. P., Fialho, A. M., Barbas, A., and Arraiano, C. M. (2009). Biochemical characterization of the RNase II family of exoribonucleases from the human pathogens Salmonella typhimurium and Streptococcus pneumoniae. Biochemistry 48, 11848-11857. doi: 10.1021/bi901105n

Erova, T. E., Kosykh, V. G., Fadl, A. A., Sha, J., Horneman, A. J., and Chopra, A. K. (2008). Cold shock exoribonuclease R (VacB) is involved in Aeromonas hydrophila pathogenesis. J. Bacteriol. 190, 3467-3474. doi: 10.1128/JB.00075-08

Even, S., Pellegrini, O., Zig, L., Labas, V., Vinh, J., Bréchemmier-Baey, D., et al. (2005). Ribonucleases J1 and J2: two novel endoribonucleases in B. subtilis with functional homology to E. coli RNase E. Nucleic Acids Res. 33, 2141-2152. doi: 10.1093/nar/gki505

Galindo, C. L., Rosenzweig, J. A., Kirtley, M. L., and Chopra, A. K. (2011). Pathogenesis of Y. enterocolitica and Y. pseudotuberculosis in Human Yersiniosis. J. Pathog. 2011, 182051. doi: 10.4061/2011/182051

Geng, J., Song, Y., Yang, L., Feng, Y., Qiu, Y., Li, G., et al. (2009). Involvement of the post-transcriptional regulator $\mathrm{Hfq}$ in Yersinia pestis virulence. PLoS ONE 4:e6213. doi: 10.1371/journal.pone.0006213

Goldstein, J., Pollitt, N. S., and Inouye, M. (1990). Major cold shock protein of Escherichia coli. Proc. Natl. Acad. Sci. U.S.A. 87, 283-287. doi: 10.1073/pnas.87.1.283

Gottesman, S., Storz, G., Rosenow, C., Majdalani, N., Repoila, F., and Wassarman, K. M. (2001). Small RNA regulators of translation: mechanisms of action and approaches for identifying new small RNAs. Cold Spring Harb. Symp. Quant. Biol. 66, 353-362. doi: 10.1101/sqb.2001.66.353

Goverde, R. L., Huis in't Veld, J. H., Kusters, J. G., and Mooi, F. R. (1998). The psychrotrophic bacterium Yersinia enterocolitica requires expression of pnp, the gene for polynucleotide phosphorylase, for growth at low temperature (5 degrees C). Mol. Microbiol. 28, 555-569. doi: 10.1046/j.1365-2958.1998.00816.x

Grunberg-Manago, M., Ortiz, P. J., and Ochoa, S. (1955). Enzymatic synthesis of nucleic acid-like polynucleotides. Science 122, 907-910. doi: 10.1126/science.122.3176.907

Guarneros, G., and Portier, C. (1991). Different specificities of ribonuclease II and polynucleotide phosphorylase in 3' mRNA decay. Biochimie 73, 543-549. doi: 10.1016/0300-9084(91)90021-R

Haddad, N., Burns, C. M., Bolla, J. M., Prévost, H., Fédérighi, M., Drider, D., et al. (2009). Long-term survival of Campylobacter jejuni at low temperatures is dependent on polynucleotide phosphorylase activity. Appl. Environ. Microbiol. 75, 7310-7318. doi: 10.1128/AEM.01366-09

Haddad, N., Tresse, O., Rivoal, K., Chevret, D., Nonglaton, Q., Burns, C. M., et al. (2012). Polynucleotide phosphorylase has an impact on cell biology of Campylobacter jejuni. Front. Cell. Infect. Microbiol. 2:30. doi: 10.3389/fcimb.2012.00030

Hankins, J. S., Denroche, H., and Mackie, G. A. (2010). Interactions of the RNA binding protein Hfq with $\operatorname{cspA}$ mRNA, encoding the major cold shock protein. J. Bacteriol. 192, 2482-2490. doi: 10.1128/JB.01619-09

Henry, A., Shanks, J., van Hoof, A., and Rosenzweig, J. A. (2012). The Yersinia pseudotuberculosis degradosome is required for oxidative stress, while its PNPase 
subunit plays a degradosome-independent role in cold growth. FEMS Microbiol. Lett. 336, 139-147. doi: 10.1111/j.1574-6968.12000.x

Huntzinger, E., Boisset, S., Saveanu, C., Benito, Y., Geissmann, T., Namane, A., et al. (2005). Staphylococcus aureus RNAIII and the endoribonuclease III coordinately regulate spa gene expression. EMBO J. 24, 824-835. doi: 10.1038/sj.emboj.7600572

Inglesby, T. V., Dennis, D. T., Henderson, D. A., Bartlett, J. G., Ascher, M. S., Eitzen, E., et al. (2000). Plague as a biological weapon: medical and public health management. Working Group on Civilian Biodefense. JAMA 283, 2281-2290. doi: 10.1001/jama.283.17.2281

Jester, B. C., Romby, P., and Lioliou, E. (2012). When ribonucleases come into play in pathogens: a survey of gram-positive bacteria. Int. J. Microbiol. 2012, 592196. doi: 10.1155/2012/592196

Jones, P. G., VanBogelen, R. A., and Neidhardt, F. C. (1987). Induction of proteins in response to low temperature in Escherichia coli. J. Bacteriol.169, 2092-2095.

Khemici, V., and Carpousis, A. J. (2004). The RNA degradosome and poly(A) polymerase of Escherichia coli are required in vivo for the degradation of small mRNA decay intermediates containing REP-stabilizers. Mol. Microbiol. 51, 777-790. doi: 10.1046/j.1365-2958.2003.03862.x

Koo, J. T., Alleyne, T. M., Schiano, C. A., Jafari, N., and Lathem, W. W. (2011). Global discovery of small RNAs in Yersinia pseudotuberculosis identifies Yersiniaspecific small, noncoding RNAs required for virulence. Proc. Natl. Acad. Sci. U.S.A. 108, E709-E717. doi: 10.1073/pnas. 1101655108

Koo, J. T., and Lathem, W. W. (2012). Global discovery of small noncoding RNAs in pathogenic Yersinia species. Adv. Exp. Med. Biol. 954, 305-314. doi: 10.1007/9781-4614-3561-7_38

Kushner, S. R. (2002). mRNA decay in Escherichia coli comes of age. J. Bacteriol. 184, 4658-4665. doi: 10.1128/JB.184.17.4658-4665.2002

Lathem, W. W. (2012). Identification of small, noncoding RNAs in pathogenic Yersinia species: implications for evolution and virulence. Virulence 3, 154-156. doi: 10.4161/viru. 19155

Lawal, A., Jejelowo, O., Chopra, A. K., and Rosenzweig, J. A. (2011). Ribonucleases and bacterial virulence. Microb. Biotechnol. 4, 558-571. doi: 10.1111/j.17517915.2010.00212.x

Lawal, A., Kirtley, M. L., van Lier, C. J., Erova, T. E., Kozlova, E. V., Sha, J., et al. (2013). The effects of modeled microgravity on growth kinetics, antibiotic susceptibility, cold growth, and the virulence potential of a Yersinia pestis ymoAdeficient mutant and its isogenic parental strain. Astrobiology 13, 821-832. doi: 10.1089/ast.2013.0968

Lehnik-Habrink, M., Lewis, R. J., Mäder, U., and Stülke, J. (2012). RNA degradation in Bacillus subtilis: an interplay of essential endo- and exoribonucleases. Mol. Microbiol. 84, 1005-1017. doi: 10.1111/j.1365-2958.2012.08072.x

Len, A. C., Harty, D. W., and Jacques, N. A. (2004). Stress-responsive proteins are upregulated in Streptococcus mutans during acid tolerance. Microbiology 150 1339-1351. doi: 10.1099/mic.0.27008-0

Lu, P., Zhang, Y., Li, L., Hu, Y., Huang, L., Li, Y., et al. (2012). Small non-coding RNA SraG regulates the operon YPK_1206-1205 in Yersinia pseudotuberculosis. FEMS Microbiol. Lett. 331, 37-43. doi: 10.1111/j.1574-6968.2012.02548.x

Mäder, U., Zig, L., Kretschmer, J., Homuth, G., and Putzer, H. (2008). mRNA processing by RNases J1 and J2 affects Bacillus subtilis gene expression on a global scale. Mol. Microbiol. 70, 183-196. doi: 10.1111/j.1365-2958.2008.06400.x

Matos, R. G., Bárria, C., Pobre, V., Andrade, J. M., and Arraiano, C. M. (2012). Exoribonucleases as modulators of virulence in pathogenic bacteria. Front. Cell. Infect. Microbiol. 2:65. doi: 10.3389/fcimb.2012.00065

Neuhaus, K., Anastasov, N., Kaberdin, V., Francis, K. P., Miller, V. L., and Scherer, S. (2003). The AGUAAA motif in $c s p A 1 / A 2$ mRNA is important for adaptation of Yersinia enterocolitica to grow at low temperature. Mol. Microbiol 50, 1629-1645. doi: 10.1046/j.1365-2958.2003.03795.x

Neuhaus, K., Rapposch, S., Francis, K. P., and Scherer, S. (2000). Restart of exponential growth of cold-shocked Yersinia enterocolitica occurs after down-regulation of cspA1/A2 mRNA. J. Bacteriol. 182, 3285-3288. doi: 10.1128/JB.182.11.3285-3288.2000

Norris, V., Menu-Bouaouiche, L., Becu, J. M., Legendre, R., Norman, R., and Rosenzweig, J. A. (2012). Hyperstructure interactions influence the virulence of the type 3 secretion system in yersiniae and other bacteria. Appl. Microbiol. Biotechnol. 96, 23-36. doi: 10.1007/s00253-012-4325-4

Oussenko, I. A., Abe, T., Ujiie, H., Muto, A., and Bechhofer, D. H. (2005). Participation of $3^{\prime}-5^{\prime}$ exoribonucleases in the turnover of Bacillus subtilis mRNA. J. Bacteriol. 187, 2758-2767. doi: 10.1128/JB.187.8.2758-2767.2005
Palanisamy, S. K., Fletcher, C., Tanjung, L., Katz, M. E., and Cheetham, B. F. (2010). Deletion of the C-terminus of polynucleotide phosphorylase increases twitching motility, a virulence characteristic of the anaerobic bacterial pathogen Dichelobacter nodosus. FEMS Microbiol. Lett. 302, 39-45. doi: 10.1111/j.15746968.2009.01831.x

Polissi, A., De Laurentis, W., Zangrossi, S., Briani, F., Longhi, V., Pesole, G., et al. (2003). Changes in Escherichia coli transcriptome during acclimatization at low temperature. Res. Microbiol. 154, 573-580. doi: 10.1016/S0923-2508 (03)00167-0

Prud'homme-Généreux, A., Beran, R. K., Iost, I., Ramey, C. S., Mackie, G. A., and Simons, R. W. (2004). Physical and functional interactions among RNase, E, polynucleotide phosphorylase and the cold-shock protein, CsdA: evidence for a 'cold shock degradosome'. Mol. Microbiol. 54, 1409-1421. doi: 10.1111/j.13652958.2004.04360.x

Purusharth, R. I., Klein, F., Sulthana, S., Jäger, S., Jagannadham, M. V., EvguenievaHackenberg, E., et al. (2005). Exoribonuclease R interacts with endoribonuclease E and an RNA helicase in the psychrotrophic bacterium Pseudomonas syringae Lz4W. J. Biol. Chem. 280, 14572-14578. doi: 10.1074/jbc.M413507200

Qu, Y., Bi, L., Ji, X., Deng, Z., Zhang, H., Yan, Y., et al. (2012). Identification by cDNA cloning of abundant sRNAs in a human-avirulent Yersinia pestis strain grown under five different growth conditions. Future Microbiol. 7, 535-547 doi: $10.2217 / \mathrm{fmb} .12 .13$

Repoila, F., and Darfeuille, F. (2009). Small regulatory non-coding RNAs in bacteria: physiology and mechanistic aspects. Biol. Cell 101, 117-131. doi: 10.1042/BC20070137

Rosenzweig, J. A., Chromy, B., Echeverry, A., Yang, J., Adkins, B., Plano, G. V., et al. (2007). Polynucleotide phosphorylase independently controls virulence factor expression levels and export in Yersinia spp. FEMS Microbiol. Lett. 270, 255-264. doi: 10.1111/j.1574-6968.2007.00689.x

Rosenzweig, J. A., Weltman, G., Plano, G. V., and Schesser, K. (2005). Modulation of yersinia type three secretion system by the S1 domain of polynucleotide phosphorylase. J. Biol. Chem. 280, 156-163. doi: 10.1074/jbc.M405662200

Schiano, C. A., Bellows, L. E., and Lathem, W. W. (2010). The small RNA chaperone $\mathrm{Hfq}$ is required for the virulence of Yersinia pseudotuberculosis. Infect. Immun. 78, 2034-2044. doi: 10.1128/IAI.01046-09

Schiano, C. A., and Lathem, W. W. (2012). Post-transcriptional regulation of gene expression in Yersinia species. Front. Cell. Infect. Microbiol. 2:129. doi: 10.3389/fcimb.2012.00129

Shimoni, Y., Friedlander, G., Hetzroni, G., Niv, G., Altuvia, S., Biham, O., et al. (2007). Regulation of gene expression by small non-coding RNAs: a quantitative view. Mol. Syst. Biol. 3, 138. doi: 10.1038/msb4100181

Silva, I. J., Saramago, M., Dressaire, C., Domingues, S., Viegas, S. C., and Arraiano, C. M. (2011). Importance and key events of prokaryotic RNA decay: the ultimate fate of an RNA molecule. Wiley Interdiscip. Rev. RNA 2, 818-836. doi: 10.1002/wrna.94

Storz, G., Vogel, J., and Wassarman, K. M. (2011). Regulation by small RNAs in bacteria: expanding frontiers. Mol. Cell 43, 880-891. doi: 10.1016/j.molcel.2011.08.022

Symmons, M. F., Jones, G. H., and Luisi, B. F. (2000). A duplicated fold is the basis for polynucleotide phosphorylase catalytic activity, processivity, and regulation. Structure 8, 1215-1226. doi: 10.1016/S0969-2126(00)00521-9

Tobe, T., Sasakawa, C., Okada, N., Honma, Y., and Yoshikawa, M. (1992). vacB, a novel chromosomal gene required for expression of virulence genes on the large plasmid of Shigella flexneri. J. Bacteriol. 174, 6359-6367.

Tsao, M. Y., Lin, T. L., Hsieh, P. F., and Wang, J. T. (2009). The 3'-to-5' exoribonuclease (encoded by HP1248) of Helicobacter pylori regulates motility and apoptosis-inducing genes. J. Bacteriol. 191, 2691-2702. doi: 10.1128/JB. 01182-08

Vanzo, N. F., Li, Y. S., Py, B., Blum, E., Higgins, C. F., Raynal, L. C., et al. (1998). Ribonuclease $\mathrm{E}$ organizes the protein interactions in the Escherichia coli RNA degradosome. Genes Dev. 12, 2770-2781. doi: 10.1101/gad.12.17.2770

Viboud, G. I., and Bliska, J. B. (2005). Yersinia outer proteins: role in modulation of host cell signaling responses and pathogenesis. Annu. Rev. Microbiol. 59, 69-89. doi: 10.1146/annurev.micro.59.030804.121320

Wang, W., and Bechhofer, D. H. (1996). Properties of a Bacillus subtilis polynucleotide phosphorylase deletion strain. J. Bacteriol. 178, 2375-2382.

Wu, J., Jiang, Z., Liu, M., Gong, X., Wu, S., Burns, C. M., et al. (2009). Polynucleotide phosphorylase protects Escherichia coli against oxidative stress. Biochemistry 48, 2012-2020. doi: 10.1021/bi801752p 
Yamanaka, K., and Inouye, M. (2001). Selective mRNA degradation by polynucleotide phosphorylase in cold shock adaptation in Escherichia coli. J. Bacteriol. 183, 2808-2816. doi: 10.1128/JB.183.9.2808-2816.2001

Yang, J., Jain, C., and Schesser, K. (2008). RNase E regulates the Yersinia type 3 secretion system. J. Bacteriol. 190, 3774-3778. doi: 10.1128/JB.00147-08

Ygberg, S. E., Clements, M. O., Rytkönen, A., Thompson, A., Holden, D. W., Hinton, J. C., et al. (2006). Polynucleotide phosphorylase negatively controls $s p v$ virulence gene expression in Salmonella enterica. Infect. Immun. 74, 1243-1254. doi: 10.1128/IAI.74.2.1243-1254.2006

Conflict of Interest Statement: The authors declare that the research was conducted in the absence of any commercial or financial relationships that could be construed as a potential conflict of interest.
Received: 04 July 2013; accepted: 30 October 2013; published online: 19 November 2013.

Citation: Rosenzweig JA and Chopra AK (2013) The exoribonuclease Polynucleotide Phosphorylase influences the virulence and stress responses of yersiniae and many other pathogens. Front. Cell. Infect. Microbiol. 3:81. doi: 10.3389/fcimb.2013.00081

This article was submitted to the journal Frontiers in Cellular and Infection Microbiology.

Copyright (C) 2013 Rosenzweig and Chopra. This is an open-access article distributed under the terms of the Creative Commons Attribution License (CC BY). The use, distribution or reproduction in other forums is permitted, provided the original author(s) or licensor are credited and that the original publication in this journal is cited, in accordance with accepted academic practice. No use, distribution or reproduction is permitted which does not comply with these terms. 